Document de Recherche du Laboratoire d'Économie d'Orléans

Working Paper Series, Economic Research Department of the University of Orléans (LEO), France

DR LEO 2019-02

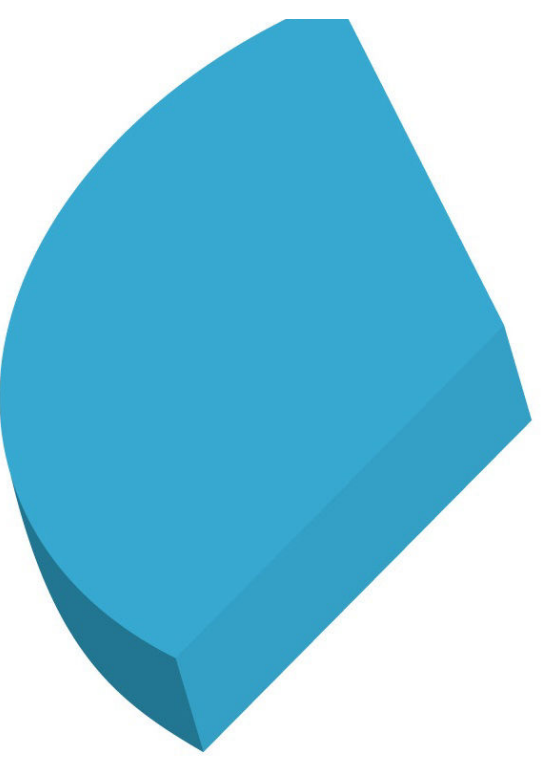

\title{
Intermittent Discounting
}

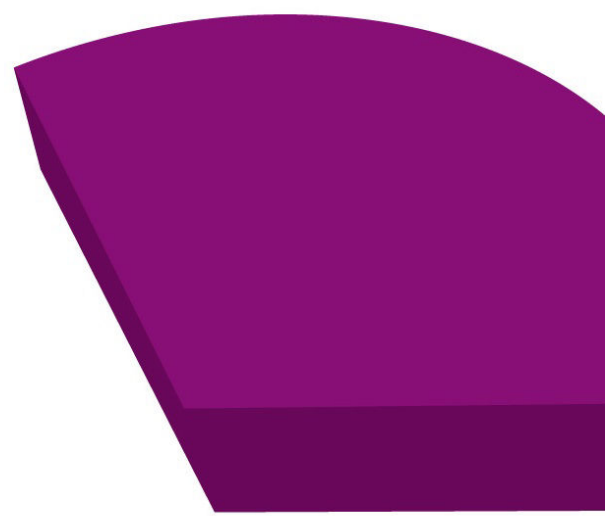

Alexis DIRER

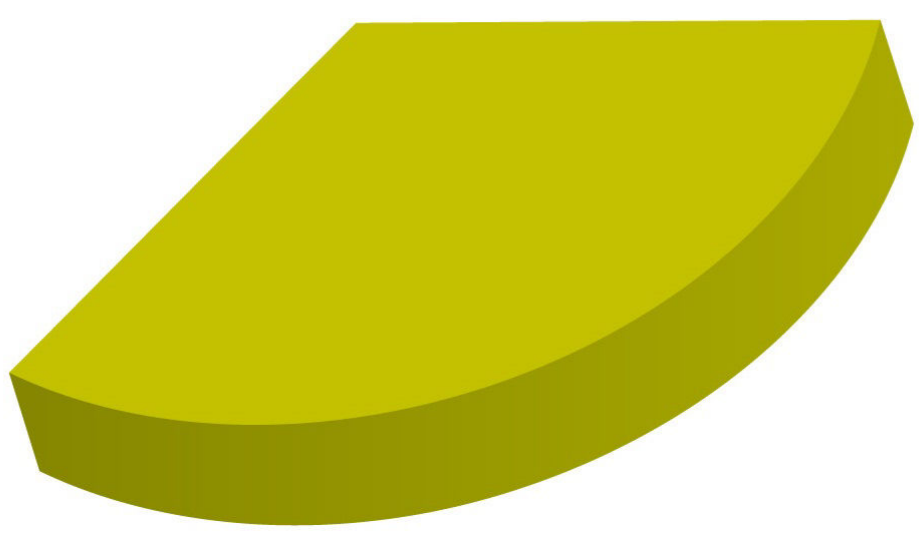

Mise en ligne / Online : 1/10/2019 


\title{
Intermittent Discounting
}

\author{
Alexis Direr *
}

September 1, 2019

\begin{abstract}
A novel theory of time discounting is proposed in which future consumption is less valuable than present consumption due to waiting costs. Waiting is intermittent as consumer's attention can be distracted away from future gratifications. The model unifies several properties of intertemporal preference like present bias, decreasing impatience or sub-additive discounting. A quantitative puzzle is presented, supported by preliminary experimental evidence, which shows how impatience over short delays may translate into excessive impatience over long delays. The waitbased model offers a solution to the puzzle, contrary to usual models of discounting.
\end{abstract}

J.E.L. codes: D8, E21

Keywords : time preferences, decreasing impatience, present bias, sub-additive discounting

${ }^{*}$ LEO, University of Orléans-CNRS, and Paris School of Economics. E-mail : alexis.direr@univorleans.fr. I thank for useful comments Louis Raffestin, participants in the 2017 European Congress of the Econometric Society and seminar participants of Laboratoire d'Economie d'Orléans and of the Chair of Integrative Risk Management and Economics at ETH Zurich. 


\section{Introduction}

Impatience is a key feature of intertemporal decisions, yet is still a versatile property. People do not like waiting two minutes at a stoplight, but are willing to save for their retirement occurring in several decades. Those contrasting attitudes suggest that the horizon of choice interacts non-linearly with individuals' propensity to discount future outcomes. This paper explores this possibility and proposes a novel theory of time discounting which starts from the observation that waiting for a reward requires a mental effort as people have to resist temptation and cope with some amount of frustration. The more delayed the gratification, the longer the waiting period and the less valuable future utility. In addition, introspection and casual observations indicate that people do not spend all their time in waiting states. Human time alternates between periods of absorption in daily activities and periods of conscious reminding of delayed gratifications during which waiting costs are truly incurred. Those may be triggered by an exogenous or external event or a cue, like discussing a new model of cell-phone with a colleague, watching a tv advertisement or contemplating a piece of chocolate fudge cake at a friend's birthday. The frequency of reminders may be reinforced by biased attention toward temptation cues. ${ }^{1}$ Reminding may also spontaneously occur when the image of a gratification springs to mind, or when a need is felt, out of boredom, discomfort, stress, hunger, thirst or craving.

When individuals experience intermittent reminding, preferences for early vs. late gratifications depend on both the disutility costs of waiting and the frequency of waiting periods. Both dimensions raise expected waiting costs and undermine consumer's willingness to delay consumption. For example, a typical question asked to people who suffer from addiction is "how many times a day do you think about ...". In less extreme situations, repeated exposure to temptation goods may lead consumers to indulge, which is routinely exploited by the advertising industry.

The goal of this paper is to investigate the implications of intermittent waiting for

\footnotetext{
${ }^{1}$ For example, smokers have been found to display selective attention for smoking-related cues (Mogg, Field, and De Houwer, 2003), and heavy drinkers toward alcohol-related cues (e.g. Townshend and Duka, 2001). See Bernheim and Rangel (2004) for a theoretical analysis.
} 
time preferences. To do so I pose a general multi-period setting in which an agent derives utility from a good which may be consumed now or later. A disutility of waiting is felt in reminding states, or "hot states" (Loewenstein, 1996), which happen in an intermittent and random fashion. The wait-based model of discounting replicates three important and robust features of intertemporal preferences: $(i)$ present bias, the propensity to prefer immediate gratification to future ones, $(i i)$ decreasing impatience (or hyperbolic discounting) according to which the rate at which an outcome is discounted over time decreases as the time horizon gets longer, (iii) non-additive discounting, when a sequence of trade-offs in a sub-divided interval leads to more overall discounting than a single trade-off over the whole interval. Present bias appears because when the present date is a planning period, it is also a waiting period. Contrary to future dates in which reminding is only a possibility, the agent feels the cost of waiting in the present when the decision to postpone a consumption is made. Intermittency of waiting means that future utility is progressively but not regularly discounted with delay. The discounting process is slowed down as a result, which makes the consumer decreasingly impatient. Discounting is sub-additive if expected waiting costs by time units are higher the shorter the time interval.

Intermittent discounting helps to solve a paradox that other models of time preference cannot. A simple formula is first presented, which determines a lower bound on longterm discounting. If an individual prefers one unit of good at date $t$ instead of $x>1$ units at date $t+1$ every period between the present and date $T$, she is also willing to forego $x^{T}$ units in $T$ periods in exchange for one unit now. The determination of the lower bound is non-parametric and applies to any discount function which decreases with delay. It may imply an excessive degree of long-term impatience as the foregone consumption $x^{T}$ is potentially quite large. I present a classroom experiment where a majority of students prefer the early option despite absurd level of long-term impatience derived from the calibrated lower bound. This apparent paradox is solved when individuals incur intermittent waiting costs. Small departure from perfect patience over short delays does not necessarily translate into strong impatience over longer delays if people are distracted most of the time by activities unrelated to the reward. 
The remainder of the paper is organized as follows. Section 2 reviews the related literature. Section 3 lays out a general model of consumption with intermittent waiting, poses a set of axioms and studies its consequences for time preferences. Section 4 investigates the link between intermittent discounting and decreasing impatience. Section 5 shows that intermittent waiting costs imply non-additive time discounting. Section 6 presents a simple experiment whose results cannot be explained by usual theories of discounting. It then shows how the waiting cost model solves the apparent puzzle. Section 7 concludes.

\section{Related Literature}

Several models of temporal discounting have been used in the literature. The constant discounting model (Samuelson, 1937) in which date $t$ utility is discounted by $\beta^{-t}$ with $\beta \in(0,1)$, is by far the most used in microeconomic or macroeconomic models. It is parsimonious and normatively appealing, yet has a limited descriptive validity (see Frederick et al. (2002) and Cohen et al. (2016) for surveys). One of the most popular model that deviates from constant discounting is quasi-hyperbolic discounting (Phelps and Pollak, 1968, Laibson, 1997), in which the discount factor is $\delta \beta^{-t}$ in future periods with $0<\delta, \beta<1$. The parameter $1 / \beta>1$ can be interpreted as an extra weight on present utility. Loewenstein and Prelec (1992) propose a generalized model of hyperbolic discounting, in which future utility is discounted by $(1+h t)^{-r / h}$ with $h \geq 0$ and $r>0$. Two special cases are proportional discounting (Mazur, 1987) when $h=r$ and power discounting (Harvey, 1986) when $h=1 .^{2}$ In this class of models, decreasing impatience holds at all dates. The present model contributes to this literature by investigating a single behavioral mechanism which explains why consumers are present biased and decreasingly impatience for remote dates.

Benhabib and Bisin (2004) introduce a separate cost of delaying consumption interpreted as "the psychological restraint from the impulse of choosing the immediate reward."

\footnotetext{
${ }^{2}$ Bleichrodt, Rohde and Wakker (2009) and Ebert and Prelec (2007) introduce discount functions which are the intertemporal analogues of constant absolute risk aversion and constant relative risk aversion utility and can also account for decreasing impatience.
} 
Contrary to the model with waiting, the cost of delay is a fixed cost independent of the size of the reward and of the length of the delay. Laibson (2001) and Bernheim and Rangel (2004) propose models of addiction in which temptation effects endogenously depend on past associations between cues (e.g. the sight of a lighter) and rewards (smoking a cigarette). The wait-based model takes as given the existence of cues, their frequency and effectiveness in triggering a behavioral response, and focuses on consequences for time preferences.

The assumption of intermittent waiting opens up the possibility of sub-additive discounting, according to which a sequence of trade-offs in a sub-divided interval leads to more overall discounting than a single trade-off over the whole interval. This pattern has been reported in several experiments ${ }^{3}$ and in German representative samples (Dohmen et al., 2012; Dohmen et al. 2017). The evidence is inconsistent with all delay-dependent discounting models, in which additivity holds regardless of the shape of the discount function. The intermittent discounting model proposes a theory of sub-additivity based on the premise that individuals expect more waiting in a series of short-delay trade-offs than in a long-delay trade-off. The explanation is consistent with the interpretation of Read (2001) according to whom sub-dividing a delay undermines people propensity to endure waiting by making them pay more attention to every part of it.

The paper is also related to the vast literature in psychology on waiting, distractions, and time perception. A body of consistent evidence shows that the perception of duration is affected by attention. The father of American psychology William James already noted in 1890: "The tracts of time (...) shorten in passing whenever we are so fully occupied with their content as not to note the actual time itself. (...) On the contrary, a day full of waiting, of unsatisfied desire for change, will seem a small eternity". Closer to us, experimental evidence shows that the ratio of judged to real duration increases when attention is stimulated. ${ }^{4}$ People who are paying attention to time itself, e.g. when they are waiting in a queue, or when they have been told in advance to estimate a period of

\footnotetext{
${ }^{3}$ Read (2001), Read and Roelofsma (2003), Scholten and Read (2006) and Kinari et al. (2009).

${ }^{4}$ See Fraisse, (1963) and Thomas and Brown (1974) for evidence. Hicks, Miller and Kinsbourne (1976) and Thomas and Weaver (1975) provide an attention-based theory of this phenomenon.
} 
time, feel the time passing more slowly. On the contrary, the ratio of judged to real time decreases when subjects are kept busy by a cognitively demanding task (Zakay and Block, 1997). If attention is distracted by non-temporal information, less capacity is available for processing temporal information (Kahneman, 1973). Katz, Larson and Larson (1991) find that distractions like watching a news board or television while waiting made the wait more acceptable for customers. In the wait-based model of discounting, people pay more attention to time in waiting states. The process of waiting causes a lengthening of the perceived temporal distance, which deepens the discount on delayed rewards.

It is also consistent with the famous "marshmallow" experiment by Mischel and Ebbesen (1970) and Mischel, Ebbesen and Raskoff Zeiss (1972), in which pre-school children were given the choice between one treat immediately or two if they waited for a short period. They found that children waited much longer for a preferred reward when they were distracted from it than when they attended to them directly (. When the rewards were out of sight, $75 \%$ of children were able to wait the full time (15 minutes). When it was exposed, the mean delay time was only about 1 minute. Successful children developed strategies of diversion like singing songs or thinking aloud. Mischel, Ebbesen and Raskoff Zeiss (1972) conclude that "attentional and cognitive mechanisms which enhanced the salience of the rewards shortened the length of voluntary delay, while distractions from the rewards, overtly or cognitively, facilitated delay."

The result that keeping in mind the reward hinders, not facilitates, the ability to control one-self, has been confirmed by multiple follow-up studies (Metcalf and Mischel, 1999). More recently, Hofmann et al. (2012) investigate with an experience sampling method how often desires in everyday life (like eating, sleeping or drinking) are felt and how often they are enacted or inhibited. They find that people who were the best at self-control reported fewer episodes of temptation rather than better ability to resist temptations. Ent et al. (2015) also show that self-control is linked to avoiding, rather than merely resisting temptation. Traditional theories of intertemporal choice have difficulties in accounting for those observations as pure time preferences are not properly distinguished from the frequency of temptations. 
Relatedly, some researchers argue that decreasing impatience reflects nonlinear perception of time. Ebert and Prelec (2007) report that making people pay more attention to the time dimension of the choice (e.g. by letting people focus on the arrival date of an item) has the effect of increasing discounting of the far future. Zauberman et al. (2009) find that making duration more salient to participants lead them to be more sensitive to time horizon, resulting in less similar preference between short and long time horizons. ${ }^{5}$

\section{$3 \quad$ Wait based preferences}

\subsection{Axioms}

A consumer decides at which date $t \in\{0, \ldots, T\}$ a good is consumed. Waiting occurs when the decision maker (DM) reminds delayed consumption in period $s=0,1, \ldots, T$ with probability $p_{s} \in[0,1]$. Waiting may occur before, but not during or after consumption: $p_{s}=0, s=t, \ldots, T$. It follows that, whatever the consumption date, the last date cannot be a waiting period: $p_{T}=0$. Preferences are defined over dated consumptions given a sequence of waiting $\left(x, t ; p_{0}, p_{1}, \ldots, p_{T-1}\right)$ where $x$ is the quantity consumed and $t$ the consumption date. Let $\succ$ be a shorthand for strict preference relations expressed at time 0 . Inverse relations $\prec$ and indifference relations $\sim$ are defined the usual way. All relations are complete and transitive. They satisfy three axioms:

Axiom 1 (Monotonicity) $\forall x, x^{\prime} \in X, x^{\prime}>x$, and $\forall t=0,1, \ldots, T,\left(x^{\prime}, t ; p_{0}, \ldots, p_{T-1}\right) \succ$ $\left(x, t ; p_{0}, \ldots, p_{T-1}\right), \forall p_{s} \in[0,1], s=0,1, \ldots, T$.

Axiom 2 (Waiting aversion) $\forall x \in X$ and $\forall t=0,1, \ldots, T,\left(x, t ; p_{0}, \ldots, p_{j}, \ldots, p_{T-1}\right) \succ$ $\left(x, t ; p_{0}, \ldots, p_{j}^{\prime}, \ldots, p_{T-1}\right), \forall p_{s} \in[0,1], s=0,1, \ldots, T$ and $p_{j}<p_{j}^{\prime}$.

Axiom 3 (Temporal indifference) $\forall x \in X$ and $\forall t=0,1, \ldots, T,\left(x, t ; p_{0}, \ldots, p_{T-1}\right) \sim$ $\left(x, t+1 ; p_{0}, \ldots, p_{T-1}\right)$ if $p_{t}=0, \forall p_{s} \in[0,1], s \neq t$.

\footnotetext{
${ }^{5}$ See also Radu et al. (2011).
} 
Axiom 1 ensures that the good is valuable to the DM for any sequence of probabilities. Axiom 2 states that the DM dislikes waiting. ${ }^{6}$ She prefers waiting to be less likely all else equal. Axiom 3 states that if date $t$ is not possibly a reminding period $\left(p_{t}=0\right)$, the DM is indifferent between consuming at this period or next period. It formalizes the intuition that consumption may be delayed effortlessly if individuals are distracted away. Axioms 2 and 3 define a weak form of impatience (see Proof in Appendix A):

Proposition 1 (Weak impatience) Under Axioms 2 and 3, $\forall x \in X$ and $\forall t=0,1, \ldots, T$, $\left(x, t ; p_{0}, \ldots, p_{T-1}\right) \succ\left(x, t+1 ; p_{0}, \ldots, p_{T-1}\right)$ if $p_{t}>0, \forall p_{s} \in[0,1], s \neq t$.

As in classic models of time discounting, an impatient DM prefers consuming the earliest period. Impatience is weak in the sense that it only happens if there is a strictly positive probability that the good is recalled to mind the period just before it is consumed. Axioms 1, 2 and 3 are model's core axioms. Additional axioms will be necessary for a few more results presented in subsequent sections. First, the DM prefers experiencing waiting as late as possible:

Axiom 4 (Preference for late waiting) $\forall x \in X, \forall t=0,1, \ldots, T,\left(x, t ; p_{0}, \ldots, p_{i}, \ldots, p_{j}, \ldots\right.$, $\left.p_{T-1}\right) \succ\left(x, t ; p_{0}, \ldots, p_{j}, \ldots, p_{i}, \ldots, p_{T-1}\right), \forall p_{s} \in[0,1], s=0,1, \ldots, t-1$ and $p_{i}<p_{j}$.

For a given average probability of waiting, the DM prefers to wait lately than early. The assumption is supported by the common observation that people tend to postpone unpleasant feelings or tasks. Second, DM preferences over the timing of waiting evolves smoothly with delay:

Axiom 5 (Preference smoothness) $\forall x \in X, \forall t=1,2, \ldots, T, \exists \beta \neq 0$ such that $\left(x, t ; p_{0}, \ldots\right.$, $\left.p_{j}, p_{j+1}, \ldots, p_{T-1}\right) \sim\left(x, t ; p_{0}, \ldots, p_{j}+\Delta, p_{j+1}-\frac{\Delta}{\beta}, \ldots, p_{T-1}\right), \forall p_{s} \in[0,1], s=0,1, \ldots, t-1$ and $\Delta \leq \min \left(1-p_{j}, \beta p_{j+1}\right), j \in\{0,1, \ldots, t-1\}$.

\footnotetext{
${ }^{6}$ Loewenstein (1987) assimilates waiting with the pleasure of savoring future consumption. While relevant in particular situations, we stick here to a more common interpretation according to which people dislike waiting.
} 
An increase or decrease of the waiting probability at date $j$ by the margin $\Delta$ lets the DM indifferent if one period later, the waiting probability is varied by the margin $\Delta / \beta$ where $\beta$ is a constant scalar common for all dates $j=0,1, \ldots, t-1$.

\subsection{Intermittent discounting}

I consider a setting in which the DM maximizes a time additive expected discounted utility function which comprises two types of utility flows: a period utility $u(x)$ from consuming $x$, increasing and twice continuously differentiable, and a disutility from waiting. If the DM delays consumption from present to date $t$, she may remind the reward with probability $p_{s}$ every period $s=0,1, \ldots, t-1$ before it is consumed. If the reward is recalled to mind, she incurs the waiting $\operatorname{costs} \delta(s, t) u(x)$, proportional to deferred utility, assuming that the more desired the prospect, the more unpleasant the waiting. Date 0 expected intertemporal utility is the sum of expected waiting costs accumulated until $t-1$ and final discounted utility:

$$
-p_{0} \delta(0, t) u(x)-p_{1} \delta(1, t) u(x)-\ldots-p_{t-1} \delta(t-1, t) u(x)+\gamma(t) u(x)
$$

where $p_{s} \delta(s, t) u(x)$ is expected disutility incurred at date $s$ of delaying consumption until $t>s . \gamma(t)$ is the discount applied to date $t$ utility when the good is eventually consumed. ${ }^{7}$ How future utility is discounted depends on the whole expected sequence of waiting.

Time preferences must satisfy Axioms 1,2 and 3. For convenience, the consequences of Axiom 3, according to which the DM is indifferent between consuming now or later in non reminding states, are first derived (see Proof in Appendix A):

Proposition 2 Under Axiom 3, temporal weights in (1) satisfy:

1. $\gamma(t+1)=\gamma(t), \forall t=0, \ldots, T-1$,

2. $\delta(s, t)=\delta(s, t+1), \forall s=0, \ldots, t-1$ and $t=1, \ldots, T-1$.

\footnotetext{
${ }^{7}$ For the sake of generality, expected utility is valued just before the DM observes whether the period 0 is a reminding period or not.
} 
The first claim means equal valuation of present and future utility. The second claim states that waiting costs depend on the date at which they are incurred, but not on the length of the remaining delay until consumption. Both results are implications of Axiom 3 which states that waiting costs are the only reason why future utility is discounted. For instance, the two sequences $\left(p_{0}, \ldots, p_{t-1} ; x\right)$ and $\left(p_{0}, \ldots, p_{t-1}, 0, \ldots, 0 ; x\right)$ are identically valued by the DM, despite different delays between the present and the consumption date or between the date of the waiting costs and the consumption date.

The notations are simplified accordingly. From now on, all $\gamma(t), t=0,1, \ldots, T$, are normalized to 1 . With probability $p_{s}$, the DM reminds consumption at date $s=0,1, \ldots, t-$ 1 and incurs the cost $\delta(s, t)=\delta_{s}$. Let us define expected utility as the product of utility and the discount factor: $D(t) u(x) . D(t)$ is the sum of weights attached to utility until date $t$ :

$$
D(t)=1-p_{0} \delta_{0}-p_{1} \delta_{1}-p_{2} \delta_{2}-\ldots-p_{t-1} \delta_{t-1}
$$

and $D(0)=1$. The constraints imposed on temporal weights by Axioms 1 and 2 are derived in Proposition 3 (see Proof in Appendix A):

Proposition 3 Under Axioms 1, 2, and 3, temporal weights $\delta_{s}, s=0,1, \ldots, T-1$, satisfy $1>1-\delta_{0}>1-\delta_{0}-\delta_{1}>\ldots>1-\delta_{0}-\delta_{1}-\ldots-\delta_{T-1}>0$.

Axiom 1 requires that consumption is valuable at every horizon, i.e. $D(t)>0 \forall t=$ $0,1, \ldots, T$, even in the less favorable environment in which the DM waits every period before consuming, that is when all probabilities are equal to 1. Proposition 3 implies that the longer the delay until consumption, the smaller the sum of temporal weights attached to utility: $D(0) \geq D(1) \geq D(2) \geq \ldots \geq D(T) \geq 0$, whatever the sequence of reminding probabilities $p_{s} \in[0,1], s=1, \ldots, T-1$.

The decrease of discount factors with delay is the classic definition of impatience in time discounting models. Here, since utility is not time discounted, impatience entirely rests on anticipated waiting costs. The further away consumption is delayed, the less expected utility, because the greater number of periods during which the DM may remind 
future consumption. The decrease is non-linear as she may expect (possibly long) periods during which consumption is not reminded.

Propositions 2 and 3 may hold for an arbitrarily large number of periods, especially when the unit of time is short, like a day or an hour. Utility postponed arbitrarily far in the future cannot be negative for any sequence of probabilities (Proposition (3)). A sufficient condition is the convergence of $D(T)$ to a positive limit with all probabilities set to 1 :

$$
\lim _{T \rightarrow \infty} 1-\delta_{0}-\delta_{1}-\ldots-\delta_{T-1} \geq 0
$$

Condition 3 extends Proposition 3 to the infinite horizon case. It implies that temporal weights $\delta_{s}$ become arbitrarily close to each other as the sequence progresses. ${ }^{8}$

Axioms 4 and 5 impose additional restrictions on waiting costs (see Proof in Appendix A):

Proposition 4 Under Axioms 1, 2, 3, 4 and 5, $\exists \beta \in(0,1)$ such that period $t$ waiting cost is $\delta_{t}=\beta^{t} \delta_{0}$, with $\delta_{0}<\frac{1-\beta}{1-\beta^{T}}$.

Waiting costs felt in the present are $\delta_{0} u(x)$. Postponed waiting costs are discounted by a factor $\beta^{t}$ which takes an exponential form. Moreover, preference for late waiting (Axiom 4) implies $\beta<1$.

\subsection{Waiting and present bias}

When reminding probabilities are time varying, not only time relative to the evaluation period matters but also events occurring in calendar time. This makes difficult disentangling in decisions what comes from time preferences per se and time-varying probabilities. In the next sections, time properties will be studied in a simplified environment in which all dates, except the present, have a constant reminding probability equal to $p$.

\footnotetext{
${ }^{8}$ Using the fact that any convergent sequence is a Cauchy sequence, for any given $\varepsilon>0$, there exists a date $T_{0}$ such that for any pair of dates $(s, t)$ satisfying $T_{0}<s<t$, we have $|D(t)-D(s)|<\varepsilon$ or $\delta_{s}+\delta_{s+1}+\ldots+\delta_{t-1}<\varepsilon$.
} 
Assumption 1 When the DM evaluates at date 0 the sequence $\left(p_{0}, p_{1}, \ldots, p_{t-1} ; x\right), t=$ $1,2, \ldots, T-1, p_{s}=p \in[0,1], s=1, \ldots, t-1$ and $p_{0} \geq p$.

Assumption 1 makes preferences time invariant ie. immune to calendar effects. The ranking at time 0 of two dated payments does not change when both the evaluation period (date 0) and the payment dates are postponed by a common delay (Fishburn and Rubistein, 1982; Halevy, 2015).

The present in Assumption 1 is a special period insofar as it is a decision or a planning date. Even if the good is not yet available, choosing between two future consumption plans may act as a cue to consume and trigger waiting costs. Planning may not necessarily entail waiting costs if the DM remains in "cold" state. Yet, the simple act of planning and thinking about the reward could make the DM feeling the wait. This creates a form of present bias, a strong appeal to consuming now vs. in any future dates (Direr, 2019), by attracting the DM attention toward the reward in the present. The probability of reminding is therefore greater than in other periods: $p_{0} \geq p$. The higher $p_{0}$ compared to $p$, the higher the bias toward the present.

The effects of present bias may be amplified by the durability bias, which is the tendency to overestimate the length of time future emotional responses will last (Gilbert et al., 1998). Even if people accurately estimate the intensity of their future emotions, they may not be able to estimate the duration of them. Durability bias is generally stronger in reaction to negative events and may be explained by the tendency to give disproportionate weight to accessible information (Schkade and Kahneman, 1998). People may focus too much on the immediate feeling and not enough on the consequences of future events that may interfere with it (Wilson er al., 2000). In the present context, the DM may think about the immediate frustration in a vacuum and fail to anticipate the many sources of distractions that may suppress the negative feeling in the near future. The effects of present bias on short-term impatience could then be increased by the belief that the psychological costs of resisting the temptation will persist a long time in the future. 


\subsection{A three parameter model}

Assumption 1 with $p_{0}=1$ simplifies the discount factor:

$$
D(t)=1-(1-p) \delta_{0}-p \delta_{0} \frac{1-\beta^{t}}{1-\beta}
$$

Three parameters govern intertemporal preferences: waiting costs $\delta_{0}$ (or the "amount" of discounting), how frequently waiting is expected to recur in the future (or the "speed" of discounting), and discount factor $\beta^{t}$ applied to future waiting costs. The smaller $\beta$ or frequency $p$, the more patient the DM. Patience is maximal if the DM does not expect to remind the reward in the future $(p=0)$, implying $D(t)=1-\delta_{0}$, or if the DM expects to remind consumption in the future $(p>0)$ but only cares about present costs of waiting $(\beta=0)$. In both cases, she displays a strong preference for present consumption but is perfectly patient when future prospects are compared. To the opposite, impatience is maximal if she expects to remind the reward every period $(p=1)$.

\section{Decreasing impatience}

\subsection{Definition}

Psychological discount rates tends to decline as people consider their preferences for longer time periods. Thaler (1981) found that to delay a $\$ 15$ lottery winning for 3 months, people required an extra $\$ 15$ (277\% annual discount rate); but to delay the same amount for 1 year, they required only an extra $\$ 45$ (139\% annual discount rate). In addition, as both early and late consumptions get closer to the present, people tend to assign progressively greater weight to early consumption relative to late consumption. These preference patterns, called decreasing impatience or hyperbolic discounting, lead to inconsistent intertemporal choices.

Formally, impatience is decreasing (increasing) if for any couple of dated consumptions $(x, t)$ and $\left(x^{\prime}, t+1\right)$ such that the DM is indifferent between them, she prefers delaying (advancing) consumption when the two dates are shifted forward by one period. 
Definition 1 (decreasing impatience) $\forall x, x^{\prime} \in X$ and $\forall t \in\{1, \ldots, T-1\}$, such that $(x, t-1) \sim\left(x^{\prime}, t\right)$, impatience is decreasing if $(x, t) \prec\left(x^{\prime}, t+1\right)$, constant if $(x, t) \sim$ $\left(x^{\prime}, t+1\right)$, or increasing if $(x, t) \succ\left(x^{\prime}, t+1\right)$.

The result of decreasing impatience is supported by most experimental studies. In an experiment, Bleichrodt, Gao, and Rohde (2016) show that a majority of subjects are decreasingly impatient and that generalized hyperbolic discounting and proportional discounting best describe time preferences. Abdellaoui et al. (2010, 2013) conclude that hyperbolic discounting performs better than constant, quasi-hyperbolic, proportional, and power discounting. Decreasing impatience has also been noted for substance abusers (Kirby, Petry, and Bickel, 1999). Based on neuroimagining, Kable and Glimcher (2007) find that hyperbolic discount functions fit behavior better than exponential discount functions. ${ }^{9}$

\subsection{Waiting and decreasing impatience}

Before investigating whether the wait-based model displays decreasing impatience, we need to specify when the DM is likely to remind consumption in trade-offs involving two delayed rewards. Assumption 1 applies to the evaluation of sequences with the present being a possible consumption date. When the DM compares two sequences involving delayed rewards, the period when the good can be consumed the first time is in the future. Much like the present in Assumption 1, the first possible period of consumption may stand out from other periods.

Assumption 2 (future trade-offs) When the DM evaluates at date 0 the two sequences $\left(x, t ; p_{0}, p_{1}, \ldots, p_{T-1}\right), t>0$ and $\left(x^{\prime}, t^{\prime} ; p_{0}, p_{1}, \ldots, p_{T-1} ;\right), t^{\prime}>t$, then $p_{s}=p \in[0,1]$, $\forall s \neq 0, t, p_{0} \geq p$ and $p_{t}=q \geq p$.

\footnotetext{
${ }^{9}$ See also Thaler (1981), Benzion, Rapoport and Yagil (1989), Green, Myerson and Mcfadden (1997), Kirby (1997) or Benhabib, Bisin, and Schotter (2010). Attema et al. (2010) and Takeuchi (2011) find non-decreasing impatience.
} 
As in Assumption 1, the probabilities of reminding are constant in non-salient periods. A second period besides the present in which reminding is more likely is assumed, which corresponds to the first date when the good is available.

When both waiting costs (Axiom 5) and probabilities (2) are smoothed, wait-based preferences exhibit decreasing impatience (see Proof in Appendix A):

Proposition 5 Under Axioms 1, 2, 3, 4, 5 and Assumption 2, impatience is decreasing.

Note that the proof requires the monotonicity condition (Axiom 1) for arbitrary horizons. $^{10}$ To get the intuition of why waiting entails decreasing impatience, consider the limit case with maximal waiting costs and infinite horizon: $\delta_{0}=1-\beta$ (see Proposition 4). The discount factor is a probability-weighted mean of two discount functions characterized by opposite properties:

$$
D(t)=(1-p) \beta+p \beta^{t}
$$

Impatience is constant with delay if reminding repeats every period $(p=1)$ but is decreasing when periods of reminding alternate with periods of distractions $(p<1)$. In the limit case where the DM does not expect to remind the good in the future $(p=0)$, the discount factor is constant and preferences display a strong form of decreasing impatience. The period subjective return rate is $\beta^{-1 / t}-1$, which rapidly converges to unity with delay $t$. Intuitively, frequent distractions slow down the discounting process and makes the DM more and more patient with regard to increasingly distant consumption.

A noteworthy consequence of formulation (5) is that wait-based preferences are stationary in the limit case when waiting costs are maximal in infinite horizon setups: $\delta_{0}=1-\beta$ (Proposition 4 with $T=\infty$ ) and waiting recurs every period $(p=1)$. In this limit case, preferences inherit the normative features of the exponential model: constant impatience, absence of choice reversal, of naiveté or self-control problems. Interestingly,

\footnotetext{
10 The contrary case is illustrated with $p=1$ and maximal waiting costs: $\delta_{0}=\frac{1-\beta^{t}}{1-\beta^{T}}$ (see Proposition
} 4). Then $D(t)=\frac{1-\beta^{T-t}}{1-\beta^{T}} \beta^{t} \geq \beta^{t}$. Impatience is increasing if $T$ is finite and asymptotically constant if $T$ is infinite. 
the usual interpretation according to which constant impatience is normatively superior to decreasing impatience is challenged when waiting costs are introduced. From a welfare perspective, the DM would like to avoid reminding too often future consumption so as to reduce waiting costs, which an exponential discounter fails to do. To the contrary, decreasing impatience signals ability of not focusing too much on future rewards.

\section{$5 \quad$ Sub-additive discounting}

\subsection{Definition}

Consider a DM who is indifferent between consuming $x$ immediately or $y$ in two periods: $(x, 0) \sim(y, 2)$. Then, by transitivity of indifference, we can find a payoff $z$ such that the DM is both indifferent between consuming $x$ immediately and $z$ in period 1 , and consuming $z$ in period 1 or $y$ in period 2: $(x, 0) \sim(z, 1) \sim(y, 2)$. With a discounted utility formulation: $D(0) u(x)=D(1) u(z)=D(2) u(y)$. The discount factor over a long period can be decomposed into a series of short-term discount factors:

$$
\frac{D(0)}{D(2)}=\frac{D(0)}{D(1)} \frac{D(1)}{D(2)}
$$

much like in finance, a long-period interest rate can be expressed as the compounding of sub-period interest rates. The relation holds for all usual time-separable discount functions $D(t)$. In a series of experiments, Read (2001), Read and Roelofsma (2003) and Scholten and Read (2006) do not confirm the equality. On average, people tend to be more impatient when confronted with multiple short-delay trade-offs in a sub-divided interval than with a single trade-off over the whole interval:

$$
\frac{D(0)}{D(2)} \leq \frac{D(0)}{D(1)} \frac{D(1)}{D(2)}
$$

The pattern has also been reported in German representative samples (Dohmen et al., 2012; Dohmen et al. 2017). Dohmen et al. (2017) find, after controlling for several potential confoundings, that a large majority of respondents have preferences consistent with sub-additivity. 
The mathematical equality (6) may not hold empirically since the discount factors $D(t), t=0,1,2$, which enter twice the equation are elicited from trade-offs with different alternative dates. Let us denote $d\left(t, t^{\prime}\right)$ the generalized discount rate applied to date $t$ utility for a trade-off between $t$ and $t^{\prime}$. Condition (7) of sub-additivity is verified if:

$$
\frac{d(0,2)}{d(2,0)} \leq \frac{d(0,1)}{d(1,0)} \frac{d(1,2)}{d(2,1)}
$$

The property and its opposite, super-additivity, are defined the following way:

Definition 2 (sub-additivity) $\forall x, z, y, y^{\prime} \in X$ and $\forall s, t, 0<s<t$, such that $(x, 0) \sim$ $(y, t),(x, 0) \sim(z, s)$ and $(z, s) \sim\left(y^{\prime}, t\right)$. Preferences are additive if $y=y^{\prime}$, sub-additive if $y<y^{\prime}$ and super-additive $y>y^{\prime}$.

Preferences are sub-additive if the latest payoff which makes the DM indifferent with immediate consumption is higher when the trade-off is broken down into two shorter trade-offs. It reflects more impatience over repeated short delays than over long horizons. Definition 2 of sub-additivity imposes a restriction on discount factors which generalizes example (8):

$$
\frac{d(0, t)}{d(t, 0)} \leq \frac{d(0, s)}{d(s, 0)} \frac{d(s, t)}{d(t, s)}
$$

The inequality holds if at least one of the following inequalities is strict: $d(0, s) \geq$ $d(0, t), d(s, t) \geq d(s, 0)$ or $d(t, 0) \geq d(t, s)$. The formulation makes discount rates a function of how far outcomes are removed from the present as in standard models of intertemporal choice (the first argument of the discount function), but also of the alternative date (the second argument). ${ }^{11}$ Usual discounting models assume $d(t, s)=D(t)$ and cannot account for sub-additivity.

Sub-additivity has profound implications for the way people discount future utility flows. The convenient parallel often made between psychological and market rates falls short. $^{12}$ Familiar methods in financial planning like continuous short-term rates com-

\footnotetext{
11 The discount factor has been interpreted as a function of $t$ and trade-off's interval $|t-s|$ (Read, 2001; or Scholten and Read, 2006). The "discounting by interval" formulation has the disadvantage of disregarding whether the alternative date is before or after date $t$.

12 The parallel was made as early as Samuelson (1937, p.156) who remarked that the subjective discount rate "bears the (...) familiar relationship to the rate of discount."
} 
pounding or annualization of discount rates estimated over different horizons may not apply to subjective discount rates. In experiments, preferences over long delays cannot be inferred from preference elicited over shorter delays. The unit of time over which choices are made becomes important. Transitivity, a cornerstone of rational choices, may be violated. For instance, assume the DM prefers the early outcome $(z, s)$ to the late one $(y, t)$. If a third dominated choice $(x, 0)$ is introduced, she may reverse her choice if $(z, s)$ is first compared to $(x, 0)$. The next subsection proposes a rationale for this class of discount factors based on waiting costs.

\subsection{Waiting and sub-additive discounting}

With intermittent waiting, the valuation of a quantity consumed in $t$ periods may depend on the alternative consumption date, if the expected sequence of waiting varies with the trade-off at hand. Condition (9) of sub-additivity expresses as:

$$
\frac{1}{1-p_{0} \delta_{0}-p_{1} \delta_{1}} \leq \frac{1}{1-p_{0} \delta_{0}} \frac{1-p_{0} \delta_{0}}{1-p_{0} \delta_{0}-q \delta_{1}}
$$

which is true if $q \geq p_{1}$. In the first trade-off with $p_{1}$, the DM compares an immediate consumption and one in date 2. Nothing special happens in period 1 during which the DM is likely to be distracted by other occupations. In the second trade-off, the DM compares consumption at dates 1 and 2. The availability of the good in period 1 makes reminding more likely: $q \geq p_{1}$. Inequality $d(2,0) \geq d(2,1)$ implies in turn sub-additivity. ${ }^{13}$ Waitbased preferences are sub-additive according to Definition 2:

Proposition 6 Under Axioms 1, 2, 3, and Assumption 2, preferences are sub-additive.

See Proof in Appendix A. The date $t$ discount factor $d(t, s)=1-p_{0} \delta_{0}-\ldots-p_{s} \delta_{s}-$ $\ldots-p \delta_{t-1}$ depends on date $0<s<t$ as it is the alternative period during which the good may be consumed. Its salience makes reminding more likely: $p_{s}=q \geq p$.

\footnotetext{
13 Read (2001) proposed a similar interpretation of sub-additivity: "The imagined pain of two days waiting, for instance, might be increased if the days are contemplated separately than together."
} 


\section{$6 \quad$ Waiting over short and long delays}

\subsection{A time preference anomaly}

The following proposition illustrates how impatience over short delays may lead to implausible impatience over longer delay (see Proof in Appendix A):

Proposition 7 Assume that $(i)$ intertemporal utility is time separable with discount factor $D(t)$, (ii) period utility has a power form: $u(x)=x^{\sigma}, \sigma>0$ and (iii) the consumer is impatient and not increasingly impatient. Let $y_{t}$ and $x_{t}$, be the maximal quantities the DM, from date 0 perspective, is willing to forego at date $t$ in exchange for one unit obtained at date 0 or $t-1$ respectively. Then $y_{t}>\left(x_{t}\right)^{t}$.

The quantity $y_{t}$, a measure of impatience over long delays, is bounded below by an amount exponentially increasing with the number of periods composing the long delay. It may grow extremely fast with horizon $t$ when the DM is not perfectly patient over short delays, ie. when $x_{t}$ departs from 1 . The relation is non-parametric as it applies to any discount function representing time additive preferences, including hyperbolic or quasi-hyperbolic models. ${ }^{14}$

How large $y_{t}$ can be is illustrated with the help of a classroom experiment conducted with 49 students. They answered during the half-time break of a three hour course a series of questions asking them whether they would prefer receiving a box of 32 smarties (color-varied sugar-coated chocolate sweets) in $n$ weeks, with $n$ ranging from 0 to 5 , or the same quantity plus one additional chocolate sweet in the same number of weeks plus one hour and a half, at the end of the session. The actual week when the confectioneries were distributed according to their answers were randomly selected by throwing a die after the questionnaires were completed. The breaks lasted 15 minutes, which gave students enough time to consume as many smarties as they wanted. The questionnaire and the

\footnotetext{
${ }^{14}$ The assumption of non-increasing impatience is considered the most plausible case. With increasing impatience, the proposition would include a short-delay trade-off between the present and date 1 . The upper bound would become $y_{t}>\left(x_{1}\right)^{t}$, which would still lead to a potentially large $y_{t}$.
} 
details of the experiment are presented in Appendix B. The fraction of students preferring receiving the chocolate sweets during the break rather than at the end of the course in function of the delay expressed in weeks is indicated in Table 1.

Table 1: Fraction of subjects preferring the early option in function of delay expressed in weeks $(N=49)$

\begin{tabular}{lcccccc}
\hline weeks & 0 & 1 & 2 & 3 & 4 & 5 \\
\hline fraction of subjects & 0.65 & 0.65 & 0.65 & 0.65 & 0.65 & 0.65 \\
\hline
\end{tabular}

Nearly two thirds of students preferred the early option to the late option whatever the number of weeks by which the trade-off was delayed. The proportion remains constant although the identity of students choosing the early option marginally changed across weeks. ${ }^{15}$ The fact that a majority of students were impatient the first session $(n=0)$ despite a substantial rate of return (around $3 \%$ over a 90 minute interval) is not uncommon in experiments involving primary rewards (e.g. Reuben, Sapienza and Zingales, 2010). Short-run impatience starting from the present is classically explained by present bias (e.g. O'Donoghue and Rabin, 2015). Yet subjects should rapidly switch to the late option when the trade-off is delayed according to standard theories of time discounting. Suppose indeed that the DM is indifferent between consuming 32 chocolate sweets in $n$ weeks and 33 in $n$ weeks plus one hour and a half. With a unit period of one hour and a half, the total number of periods over $n$ weeks plus one hour and a half is $t=7 \times 16 \times n+1=112 n+1$. Assuming indifference between the early and late options: $D(t-1) u(32)=D(t) u(33)$, Proposition 7 demonstrates with linear or power utility that $y_{t}$ in the long-delay trade-off is bounded below by $x^{t}=(33 / 32)^{t}=1.031^{t}$.

Table 2: Lower bound in the long-delay trade-off in function of the number of weeks

\begin{tabular}{lcccccc}
\hline number of weeks $(n)$ & 0 & 1 & 2 & 3 & 4 & 5 \\
\hline number of sub-periods $(t)$ & 1 & 113 & 225 & 337 & 449 & 561 \\
lower bound of $y_{t}\left(x^{t}\right)$ & 1.031 & 32.4 & 1,016 & 31,890 & $1,000,965$ & $31,418,282$ \\
\hline
\end{tabular}

\footnotetext{
15 see Appendix B for detailed results.
} 
The bound grows extremely fast with the number of weeks. While preferring 32 chocolate sweets against 33 in short-delay trade-offs does not seem unreasonable (at least according to most students enrolled in the experiment), the lower bounds in Table 2 reveal absurd degrees of impatience in long-delay trade-offs. For $n=5$, the DM is willing to forego more than 31 million of chocolate sweets in exchange for a single unit now. Likewise, a respondent who prefers the early distribution in $n$ weeks may find reasonable to still prefer the early option in $n+1$ weeks. Yet the theory shows dramatic changes in terms of foregone consumption, as the lower bound is multiplied by around 32 every time the trade-off is moved forward by one week. The quantitative puzzle is an issue for all additive discounting functions (exponential, hyperbolic, quasi-hyperbolic, ...).

A complementary questionnaire estimated students' degree of impatience in long-delay trade-offs. Students were asked during the break of the first session how many smarties they would like to receive in $n$ weeks plus one hour and a half, with $n$ ranging from 0 to 5 , that would make them indifferent with receiving immediately a box of 32 smarties. $^{16}$ The average quantities are reported in Table 3.

Table 3: Average number of chocolate sweets in $n$ weeks plus one hour and a half equivalent to 32 units (second row) or one unit (third row) immediately $(N=49)$

\begin{tabular}{lcccccc}
\hline number of weeks & 0 & 1 & 2 & 3 & 4 & 5 \\
\hline quantities equivalent to 32 sweets now & 39 & 52 & 64 & 77 & 93 & 115 \\
quantities equivalent to 1 sweet now & 1.22 & 1.62 & 2.00 & 2.41 & 2.91 & 3.60 \\
\hline
\end{tabular}

Although respondents show significant impatience over long-delay trade-offs, their choices strongly violate the lower bounds computed in Table 2. The quantities approximately follow a linear trend, not an exponential one.

Rubinstein (2003) made a similar point in an experiment in which subjects had to choose between receiving $\$ 467$ far in the future (around one year and a half) or $\$ 467.39$ at the same date plus one day. A majority of subjects chose the early option. As noted

\footnotetext{
${ }^{16}$ Contrary to the first experiment, the questions were hypothetical. See Appendix B for a description of the experiment.
} 
by Rubinstein, the difference between the two payoffs is small enough that turning down the greater sum even for one day seems justified. He then shows that the same subjects tended to choose the late outcome in longer delay trade-offs, which is inconsistent with their first answer, even according to the more general hyperbolic discounting function.

The anomaly exists insofar as people tend to depart from perfect patience over short delays in the future. The literature on present bias provides evidence that people reveal a strong preference for immediate rewards which fades away when the trade-off is delayed. Yet the literature does not conclude that individuals are perfectly patient, or even close to be, for postponed trade-offs. In addition to the experimental evidence presented in Table 2, other articles find that impatience does not decrease or decreases only slowly with trade-off's horizon. Halevy (2015) documents a stable discounting rate of approximately $4 \%$ over a one-week interval for an immediate trade-off and a second one deferred four weeks later. Kinari, Ohtake and Tsutsui (2009) estimate a discount rates over two-week intervals for delays up to 8 weeks and find that impatience is slowly decreasing with delay. The next subsection shows to what extent the quantitative puzzle may be solved by the wait-based model.

\subsection{Waiting and short-delay trade-offs}

Excessive impatience over long delays inferred from short-delay trade-offs seems to constitute a quantitative puzzle. Turning down the postponed option in a short-delay trade-off means that the discounting function must quickly diminish over longer delays, implying a rapidly increasing degree of impatience. ${ }^{17}$

The computation of the lower bound in Proposition 7 rests on the equality (see Proof in Appendix A):

$$
u\left(y_{t}\right)=\frac{D(0)}{D(t)}=\frac{D(0)}{D(1)} \frac{D(1)}{D(2)} \ldots \frac{D(t-1)}{D(t)}
$$

which is only valid when discounting is time additive. To understand why additivity

\footnotetext{
${ }^{17}$ Readers will remark a formal parallelism between the present analysis on small-delay aversion and Rabin (2000)'s calibration theorem for small-risk aversion.
} 
is problematic in the present context, recall that impatience is elicited with a specific treatment: subject's attention is caught and oriented toward a vivid choice at a date where consumption is feasible. A discount rate $\frac{D(t-1)}{D(t)}$, high by design, is inferred from subjects' answers. Yet, the methodology becomes questionable when the estimate is extrapolated to compute from date 0 the whole sequence of short-delay discount rates $\frac{D(s-1)}{D(s)}$.

Section 5 shows that sub-additivity connects short and long-delay impatience in a non linear way, which may reconcile the experimental evidence with minimal rationality of intertemporal choices. With sub-additive preferences, short-delay impatience is elicited with the same treatment, yet the estimate is not directly used to infer impatience over other short-delay periods.

When preferences are sub-additive, Condition (9) can be iterated forward by progressively subdividing in smaller parts the time interval between 0 and $t$ :

$$
\begin{aligned}
u\left(y_{t}\right) & =\frac{d(0, t)}{d(t, 0)} \leq \frac{d(0,1)}{d(1,0)} \frac{d(1, t)}{d(t, 1)} \\
& \leq \frac{d(0,1)}{d(1,0)} \frac{d(1,2)}{d(2,1)} \frac{d(2, t)}{d(t, 2)} \\
& \leq \ldots \\
& \leq \frac{d(0,1)}{d(1,0)} \frac{d(1,2)}{d(2,1)} \cdots \frac{d(t-1, t)}{d(t, t-1)} \\
& =u\left(y_{t}^{\prime}\right)
\end{aligned}
$$

Impatience over a time interval subdivided in $s$ parts is weaker than impatience over the same overall interval subdivided in $s+1$ parts. As a result, the quantity $y_{t}$ derived from the long-run trade-off can potentially be much smaller than the quantity $y_{t}^{\prime}$ derived from a sequence of short-delay trade-offs, potentially solving the puzzle of Sub-section 6.1. With wait-based discounting, the short-delay discount rate cannot be extrapolated to other periods because in those periods, waiting is unlikely and people may show more patience.

We investigate whether the wait-based model may quantitatively solve the puzzle. Assuming linear utility, the quantity $x_{s}$ which makes the DM indifferent between consuming 
one unit at date $s-1$ and units next period is:

$$
x_{s}=\frac{1-p_{0} \delta_{0}-p \delta_{1}-\ldots-p \delta_{s-1}}{1-p_{0} \delta_{0}-p \delta_{1}-\ldots-p \delta_{s-1}-q \delta_{s-1}}
$$

with $p_{0}, q \geq p$. Indifference between consuming one unit at date 0 and $y_{t}$ in $t$ periods gives:

$$
y_{t}=\frac{1}{1-p_{0} \delta_{0}-p \delta_{1}-\ldots-p \delta_{t-1}}
$$

Besides the present, the long-delay trade-off only includes non-salient periods whereas every short-delay trade-off has a salient period at the beginning of the trade-off during which waiting is likely, as reflected by a higher probability $q \geq p$.

In the calibration, temporal weights satisfy $\delta_{t}=\beta^{t} \delta_{0}$, with $\delta_{0}>0$ the undiscounted waiting cost and $\beta \in(0,1)$ the one period discount factor applied to future waiting costs (see Proposition 4). ${ }^{18}$ Respondents are presumed to remind the reward when they have to choose between two delayed alternatives: $p_{0}=1$. The current session may actually be selected, which makes consuming the chocolate sweets in a few minutes a real possibility. For consistency, respondents are also assumed to remind consumption when the questionnaire with long-delay trade-offs is filled. Model's parameters take values: $\alpha=0.18, \beta=0.9996, p=0.006$ and $q=0.1$, so that numerical quantities $x_{s}$ in Eq. (10) and $y_{t}$ in Eq. (11) fit best the experiment's rate of return $x_{t}=1.031$, and average quantities $y_{t}$ from Table 3. Table 4 presents the results.

Table 4: Model's fit of average quantities $y_{t}$ in long-delay trade-offs (Table 3 ) and experiment's rate of return $x=1.031$

\begin{tabular}{lcccccc}
\hline number of weeks $(n)$ & 0 & 1 & 2 & 3 & 4 & 5 \\
\hline equivalence to 1 sweet now $\left(y_{t}\right)$ & 1.22 & 1.62 & 2.00 & 2.41 & 2.91 & 3.60 \\
model's values for $y_{t}$ & 1.22 & 1.43 & 1.70 & 2.08 & 2.65 & 3.59 \\
model's rate of return $\left(x_{s}\right)$ & 1.022 & 1.025 & 1.029 & 1.034 & 1.041 & 1.054 \\
\hline
\end{tabular}

The implicit return's rate $x_{s}$ is somewhat too low for horizons shorter than 3 weeks compared to the experiment's rate of return 1.031, and too high for longer horizons. The 18 The monotonicity constraint $\delta_{0}<\frac{1}{1-\beta^{T}}$ in Proposition 4 is satisfied in the calibration. 
quantities $y_{t}$ are moderately too low for weeks 1 to 4 . Overall, although not perfect, the calibrated model is approximately consistent with choices, and performs far better than time additive discounting models.

The parameter's values which fits best respondent's choices do not seem implausible. We have seen that preferences with waiting costs are sub-additive if people remind less frequently future consumption in non salient periods than in salient ones. This is the case here with a non salient reminding probability equal to $p=0.006$ and salient ones to $q=0.1$ which is 17 times much higher. Given the magnitude of $p$, we may actually expect most subjects to forget altogether the promised sweets until their distribution in $n$ weeks. Reminding the reward entails a disutility equivalent to nearly one fifth $(\alpha=0.18)$ of the utility of consumption. This implies that the DM would prefer not consuming the sweets if she could avoid six episodes of temptation in the near future before consuming them. The disutility is only weakly discounted, with a discount factor equal to $\beta=0.9996$. This implies that the disutility of waiting postponed by one week is reduced by a factor of $0.9996^{112}=0.956$, or a factor of $0.9996^{448}=0.836$ if postponed by four weeks.

\section{Conclusion}

A novel theory of time discounting is proposed in which intertemporal trade-offs depend on two dimensions: the size of waiting costs and how frequently waiting is expected to repeat. Delaying consumption implies more waiting and as a result less utility net of waiting costs. While other economic models of discounting treat time as a continuous flow, the model adopts a nonlinear approach, more familiar to psychologists, in which experienced time elapses only when attention to future gratifications is paid. As stressed by Stout (1932): "In general, temporal perception is bound up with the process of attention... What measures the lapse of time is the cumulative effect of the process of attending". This interpretation is backed by the equivalence found in the model between the classical model of exponential discounting and a version of the wait-based model in which reminding recurs every period and time is elapsing linearly. It is consistent with 
experimental evidence beginning with Mischel, Ebbesen and Raskoff Zeiss (1972) who show that pre-school children waited much longer for a preferred reward when they were distracted from it than when they attended to it.

A single psychological mechanism based on disutility of waiting accounts for important properties of time preferences like present bias or decreasing impatience. As a planning or decision date, the present is likely to be a waiting period, which strengthens shortterm impatience. Intermittent waiting means that future utility is progressively but not regularly discounted with the passing of time. Intermittence slows down the discounting process, makes people less impatient, and even less when the front-end delay is stretched.

The model also proposes an explanation for sub-additive discounting. Sub-additivity has important consequences for the link between short and long-delay discounting. It implies that discount rates over long horizons are only weakly connected to discount rates over short horizons. It also helps to bridge the gap between high short-term impatience found in experiments and low interest rates at the macroeconomic level, a point stressed by Cochrane (2011): "People report astounding discount rates in surveys and experiments, yet still own long-lived assets, houses, and durable goods." With intermittent waiting, short-delay trade-offs involve proportionately more waiting than long-delay trade-offs. This helps solve an anomaly which the paper describes, supported by preliminary experimental evidence. The anomaly is quantitative and presents a challenge for all additive models of time discounting. The solution proposed is based on the intuition that expressing impatience in short-delay trade-off does not imply strong impatience in longer delays, as individuals forget the reward most of the time.

Researchers have documented sharp differences in intertemporal choice across individuals, groups and tasks (Fredericks et al., 2002), which are primarily interpreted as variability in discount rates. A significant source of heterogeneity may however come from the frequency with which individuals remind future gratifications. Smokers (Baker, Johnson and Bickel, 2003), alcoholics (Vuchinich and Simpson, 1998) or substance-dependent individuals (Kirby, Petry, and Bickel, 1999) show large discounting of delayed rewards but are also presumed to remind the addictive substance many times a day. The paper 
does not explain why some people experience more temptation episodes than others. Addiction, weak habits, or genetic predispositions may be part of the story. Some people seem better able to avoid potential conflicts, e.g. by installing adaptive routines (Gillebaart and de Ridder, 2015). It would be interesting to design experiments which would separately estimate pure discount rates from frequency of temptations. 


\section{References}

Attema A. E., Bleichrodt H., Rohde K. I. M. and P. P. Wakker (2010) "Time-tradeoff sequences for analyzing discounting and time inconsistency" Management Science, 56, 2015-2030.

Baker F., Johnson M. W. and W. K. Bickel (2003) "Delay discounting in current and never-before cigarette smokers: similarities and differences across commodity, sign, and magnitude" Journal of Abnormal Psychology 112 (3), 382-392.

Benhabib J. and A. Bisin (2004) "Modelling Internal Commitment Mechanisms and Self-Control: A Neuroeconomics Approach to Consumption-Saving Decision" Games and Economic Behavior, 52 (2), 460-492.

Benhabib J., A. Bisin and A. Schotter (2010) "Present-Bias, Quasi-Hyperbolic Discounting, and Fixed Costs" Games and Economic Behavior, 69 (2), 205-223.

Benzion U., A. Rapoport and J. Yagil (1989) "Discount Rates Inferred From Decisions: An Experimental Study" Management Science 35, pp. 270-84.

Bernheim B. D. and A. Rangel (2004) "Addiction and cue-triggered decision processes" American Economic Review, 94(5), 1558-1590.

Bleichrodt H., Y. Gao, and K. I. M. Rohde (2016) "A measurement of decreasing impatience for health and money" Journal of Risk and Uncertainty 52 (3), 213-231.

Bleichrodt H., K. I. M. Rohde and P. P. Wakker (2009) "Non-hyperbolic time inconsistency" Games and Economic Behavior 66, 27-38.

Cochrane J. H. (2011) "Presidential Address: Discount Rates" The Journal of Finance, 66 (4), 1047-1108.

Cohen J., Ericson K. M., Laibson D. and J. M. White (2019) "Measuring Time Preferences", Journal of Economic Literature Forthcoming.

Direr A. (2019) "Present bias: Definition and measurement", working paper.

Dohmen T., Falk A., Huffman D. and U. Sunde (2012) "Interpreting Time Horizon 
Effects in Inter-Temporal Choice", IZA working paper 6385.

Dohmen T., Falk A., Huffman D. and U Sunde (2017) "The robustness and pervasiveness of sub-additivity in intertemporal choice", working paper.

Ebert J. E. J. and D. Prelec (2007) "The fragility of time: time-insensitivity and valuation of the near and far future" Management Science, 53, 1423-1438.

Ent M. R., Baumeister R. F., and D. M. Tice (2015) "Trait self-control and the avoidance of temptation" Personality and Individual Differences, 74, 12-15.

Fishburn P. C, and A. Rubinstein (1982) "Time preference" International Economic Review 23(3) 677-694.

Fraisse P. (1963) The psychology of time. New York: Harper and Row.

Frederick S., Loewenstein G., and T. O’Donoghue (2002) "Time discounting and time preference: A critical review" Journal of economic literature, pp. 351-401.

Gillebaart M. and D. T. D. de Ridder (2015) "Social and Personality Psychology Compass" 9 (2), 88-99.

Gilbert D. T., Pinel E. C., Wilson T. D., Blumberg S. J. and T. P. Wheatley (1998) "Immune neglect: A source of durability bias in affective forecasting", Journal of Personality and Social Psychology, 75 (3), 617-638.

Green L., J. Myerson and E. Mcfadden (1997) "Rate of Temporal Discounting Decreases with Amount of Reward" Memory and Cognition 25 (5), 715-23.

Harvey C. M. (1986) "Value functions for infinite period planning" Management Science $32,1123-39$.

Halevy Y. (2015) "Time Consistency: Stationarity and Time Invariance" Econometrica, 83(1), 335-352.

Hicks R. E., Miller G. W. and M. Kinsbourne (1976) "Prospective and retrospective judgments of time as a function of amount of information processed" American Journal of Psychology, 89, 719-730. 
Hofmann W., Baumeister R. F., Förster G. and K. D. Vohs (2012) "Everyday temptations: an experience sampling study of desire, conflict, and self-control" Journal of Personality and Social Psychology 102 (6), 318-35.

James W. (1890) The Principles of Psychology, Dover Publications 1950, chapter XV.

Kable J. W. and P. W. Glimcher (2007) "The Neural Correlates of Subjective Value during Intertemporal Choice" Nature Neuroscience 10 (12), 1625-33.

Kahneman D. (1973) Attention and effort. Englewood Cliffs, NJ: Prentice-Hall.

Katz K., Larson B. and R. Larson (1991) "Prescriptions for the Waiting-in-Line Blues: Entertain, Enlighten and Engage" Sloan Management Review 32, 44-53.

Kinari Y., Ohtake F. and Y. Tsutsui (2009) "Time discounting: Declining impatience and interval effect" Journal of Risk and Uncertainty, 39 (1), 87-112.

Kirby K. N. (1997) "Bidding on the Future: Evidence against Normative Discounting of Delayed Rewards" Journal of Experimental Psychology: General 126 (1), 54-70.

Kirby K. N., Petry N. M., and W. K. Bickel (1999) "Heroin addicts have higher discount rates for delayed rewards than non-drug-using controls" Journal of Experimental Psychology: General, 128 (1), 78-87.

Koopmans T. C. (1960) "Stationary ordinal utility and impatience" Econometrica, 28, 287-309.

Laibson D. (1997) "Golden Eggs and Hyperbolic Discounting" Quarterly Journal of Economics, 112 (2), 443-478.

Laibson D. (2001) "A Cue-Theory of Consumption" Quarterly Journal of Economics $116(1), 81-119$.

Loewenstein G. (1987) "Anticipation and the Valuation of Delayed Consumption" Economic Journal, 97 (387), 666-684.

Loewenstein G. (1996) "Out of Control: Visceral Influences on Behavior," Organizational Behavior and Human Decision Processus 65, 272-92. 
Loewenstein, G. and D. Prelec (1992) "Anomalies in Intertemporal Choice: Evidence and an Interpretation" Quarterly Journal of Economics 107 (2), 573-597.

Mazur J. E. (1987) "An Adjustment Procedure for Studying Delayed Reinforcement" in The Effect of Delay and Intervening Events on Rein forcement Value. Michael L. Commons, James E. Mazur, John A. Nevin and Howard Rachlin, eds. Hillsdale, NJ: Erlbaum.

McClure S. M., Ericson K. M., Laibson D. I., Loewenstein G. and J. D. Cohen (2007) "Time Discounting for Primary Rewards" Journal of Neuroscience 27 (21), 5796-5804.

Metcalf J. and W. Mischel (1999) "A Hot/Cool-System Analysis of Delay of Gratification: Dynamics of Willpower" Psychological Review 106 (1) 3-19.

Mischel W. and E. B. Ebbesen (1970) "Attention in Delay of Gratification" Journal of Personality and Social Psychology 16 (2), 329-37.

Mischel W., Ebbesen E. B. and A. Raskoff Zeiss (1972) "Cognitive and attentional mechanisms in delay of gratification" Journal of Personality and Social Psychology 21 (2), 204-21.

Mogg K. B., Field B. P., and J. De Houwer (2003) "Eye movements to smokingrelated pictures in smokers: Relationship between attentional biases and implicit and explicit measures of stimulus valence" Addiction, 98, 825-836.

O'Donoghue T. and M. Rabin (2015) "Present Bias: Lessons Learned and To Be Learned" American Economic Review: Papers 6 Proceedings, 105 (5), 273-279.

Phelps E. S. and R. A. Pollak (1968) "On Second-Best National Saving and GameEquilibrium Growth" Review of Economic Studies, 35 (2), 185-199.

Rabin M. (2000) "Risk aversion and expected-utility theory: A calibration theorem" Econometrica, 68 (5), 1281-92.

Radu P. T., Yi R., Bickel W. K., Gross J. J. and S. M. McClure (2011) "A Mechanism for Reducing Delay Discounting by Altering Temporal Attention" Journal of the Experimental Analysis of Behavior, 96 (3), 363-385. 
Read D. (2001) "Is Time-Discounting Hyperbolic or Subadditive?" Journal of Risk and Uncertainty, 23 (1), 5-32.

Read D. and P. Roelofsma (2003) "Subadditive versus Hyperbolic Discounting: A Comparison of Choice and Matching" Organizational Behavior and Human Decision Processes 91 (2), 140-53.

Reuben E., Sapienza P. and L. Zingales (2010) "Time Discounting for Primary and Monetary Rewards" Economics Letters 106 (2), 125-27.

Rubinstein D. (2003) "Economics and Psychology? The case of Hyperbolic Discounting" International Economic Review 44 (4), 1207-16.

Samuelson P. (1937) "A Note on Measurement of Utility" Review of Economic Studies $4(2), 155-61$.

Schkade D. A. and D. Kahneman (1998) "Does Living in California Make People Happy? A Focusing Illusion in Judgments of Life Satisfaction", Psychological Science 9 (5), 340-346.

Scholten M. and D. Read (2006) "Discounting by Intervals: A Generalized Model of Intertemporal Choice" Management Science 52 (9), 1424-36.

Stout G. F. 1932. A Manual of Psychology. London: W. B. Clive, University Tutorial Press Ltd.

Takeuchi K. (2011) "Non-parametric test of time consistency: Present bias and future bias" Games and Economic Behavior 71, 456-478.

Thaler R. H. (1981) "Some Empirical Evidence on Dynamic Inconsistency" Economic Letters 8, 201-07.

Thomas E. A. and T. I. Brown (1974) "Time perception and the filled-duration illusion" Perception and Psychophysics, 16, 449-458.

Thomas E. A. and W. B. Weaver (1975) "Cognitive processing and time perception" Perception and Psychophysics, 17, 363-367. 
Townshend J. and T. Duka (2001) "Attentional bias associated with alcohol cues: Differences between heavy and occasional social drinkers" Psychopharmacology, 157, 6774 .

Vuchinich R. E. and C. A. Simpson (1998) "Hyperbolic temporal discounting in social drinkers and problem drinkers" Experimental and Clinical Psychopharmacology 6 (3) 292305.

Wilson T. D., Wheatley, T. P., Meyers J. M., Gilbert D. T. and D. Axsom (2000) "Focalism: A source of durability bias in affective forecasting", Journal of Personality and Social Psychology, 78(5), 821-836.

Zakay D. and R. A. Block (1997) "Temporal cognition" Current Directions in Psychological Science, 6, 12-16.

Zauberman G. B., K. Kim, S. Malkoc and J. R. Bettman (2009) "Discounting Time and Time Discounting: Subjective Time Perception and Intertemporal Preferences" Journal of Marketing Research 46, 543-56. 


\section{Appendix A. Proofs of Propositions}

Proposition 1. Under Axioms 2 and 3, $\forall x \in X$ and $\forall t=0,1, \ldots, T,\left(x, t ; p_{0}, \ldots, p_{T-1}\right) \succ$ $\left(x, t+1 ; p_{0}, \ldots, p_{T-1}\right)$ if $p_{t}>0, \forall p_{s} \in[0,1], s \neq t$.

Proof. $\left(x, t ; p_{0}, \ldots, p_{t}^{\prime}, \ldots, p_{T-1}\right) \sim\left(x, t+1 ; p_{0}, \ldots, p_{t}^{\prime}, \ldots, p_{T-1}\right)$ if $p_{t}^{\prime}=0$ (Axiom 3) and $\left(x, t+1 ; p_{0}, \ldots, p_{t}^{\prime}, \ldots, p_{T-1}\right) \succ\left(x, t+1 ; p_{0}, \ldots, p_{t}, \ldots, p_{T-1}\right)$ if $p_{t}>p_{t}^{\prime}=0$ (Axiom 2).

Proposition 2. Under Axiom 3, temporal weights in (1) satisfy: $(i) \gamma(t+1)=\gamma(t)$ $\forall t=0, \ldots, T-1$, and $(i i) \delta(s, t)=\delta(s, t+1), \forall s=0, \ldots, t-1$ and $t=1, \ldots, T-1$.

Proof. Consuming $x$ at date 0 or 1 are equivalent if $\gamma(0) u(x)=-p_{0} \delta(0,1) u(x)+\gamma(1) u(x)$. With $p_{0}=0, \gamma(0)=\gamma(1)$. Consuming $x$ at date 1 or 2 are equivalent if

$$
-p_{0} \delta(0,1) u(x)+\gamma(1) u(x)=-p_{0} \delta(0,2) u(x)-p_{1} \delta(1,2) u(x)+\gamma(2) u(x)
$$

With $p_{1}=0, \gamma(2)-\gamma(1)-p_{0}(\delta(0,2)-\delta(0,1))=0$. The equality must hold whatever $p_{0} \in[0,1]$, hence $\delta(0,2)=\delta(0,1)$ and $\gamma(2)=\gamma(1)$. Likewise, indifference between dates $t=2, \ldots, T-1$ and $t+1$, with $p_{t}=0$, implies

$$
\begin{aligned}
& \gamma(t+1)-\gamma(t)-p_{0}(\delta(0, t+1)-\delta(0, t))-p_{1}[(\delta(1, t+1)-\delta(1, t)) \\
& -\ldots-p_{t-1}(\delta(t-1, t+1)-\delta(t-1, t))=0
\end{aligned}
$$

Those equalities must hold for any reminding probabilities $\left\{p_{0}, p_{1}, \ldots, p_{t-1}\right\} \in[0,1]^{T}$. Hence for any $s=0, \ldots, t-1$ and $t=1, \ldots, T-1: \delta(s, t)=\delta(s, t+1)$, and for any $t=1, \ldots, T-1: \gamma(t)=\gamma(t+1)$.

Proposition 3. Under Axioms 1, 2, and 3, temporal weights $\delta_{s}, s=0,1, \ldots, T-1$, satisfy $1>1-\delta_{0}>1-\delta_{0}-\delta_{1}>\ldots>1-\delta_{0}-\delta_{1}-\ldots-\delta_{T-1}>0$.

Proof. Under Axiom 1, $x^{\prime}$ is strictly preferred to $x$ at date $t=0,1, \ldots, T$ if

$$
\left(1-p_{0} \delta_{0}-\ldots-p_{t-1} \delta_{t-1}\right)\left(u\left(x^{\prime}\right)-u(x)\right)>0
$$


This holds for any vector of probabilities $\left(p_{0}, p_{1}, \ldots, p_{t-1}\right) \in[0,1]^{t}$ if

$$
1-\delta_{0}-\delta_{1}-\ldots-\delta_{t-1}>0 \quad t=0,1, \ldots, T
$$

Under Axiom 2, the sequence $\left(x, t ; p_{0}, \ldots, p_{j}, \ldots, p_{T-1}\right)$ is preferred to $\left(x, t ; p_{0}, \ldots, p_{j}^{\prime}, \ldots, p_{T-1}\right)$ with $p_{j}<p_{j}^{\prime}$ if $\left(1-p_{0} \delta_{0}-\ldots-p_{j} \delta_{j}-\ldots-p_{t-1} \delta_{t-1}\right) u(x)>\left(1-p_{0} \delta_{0}-\ldots-p_{j}^{\prime} \delta_{j}-\ldots-p_{t} \delta_{t}\right) u(x)$, or $p_{j} \delta_{j}<p_{j}^{\prime} \delta_{j}$, which is true if $\delta_{j}>0$. Together with inequality (12), they prove Proposition 3 .

Proposition 4. Under Axioms 1, 2, 3, 4 and 5, $\exists \beta \in(0,1)$, such that period $t$ waiting cost is $\delta_{t}=\beta^{t} \delta_{0}$, with $\delta_{0}<\frac{1-\beta}{1-\beta^{T}}$.

Proof. Proposition 3 implies $D(t)=1-p_{0} \delta_{0}-p \delta_{1}-\ldots-p \delta_{t-1}$. Axiom 5 implies $p_{j} \delta_{j}+p_{j+1} \delta_{j+1}=p_{j}\left(\delta_{j}+\Delta\right)+p_{j+1}\left(\delta_{j+1}-\frac{\Delta}{\beta}\right), \forall j \in\{0,1, \ldots, t-2\}$. Hence $\delta_{j+1}=\beta \delta_{j}=$ $\beta^{j} \delta_{0}$. Axiom 4 implies $\beta \in(0,1)$. Last, $D(t)>0 \forall t \leq T$ and $\forall p_{s}, s=0,1, \ldots, t-1$ (Axiom 1). $D(t)$ is minimal for $t=T$ and all $p_{s}=1$, hence $\delta_{0}<\frac{1-\beta}{1-\beta^{T}}$.

Proposition 5. Under Axioms 1, 2, 3, 4, 5 and Assumption 2, impatience is decreasing.

Proof. The DM is decreasingly impatient according to Definition 1 if, $\forall t=1, \ldots, T-1$ :

$$
\frac{D(t)-p_{t} \delta_{t}}{D(t)}<\frac{D(t)-p \delta_{t}-p_{t+1} \delta_{t+1}}{D(t)-p \delta_{t}}
$$

with $D(t)=1-p_{0} \delta_{0}-p \delta_{1}-\ldots-p \delta_{t-1}$. As the left-hand side trade-off begins at date $t$, $p_{t}=q \geq p$. The right-hand side trade-off begins one period later, hence $p_{t+1}=q$. The condition simplifies to

$$
\frac{\delta_{t}-\delta_{t+1}}{\delta_{t}}>\frac{p \delta_{t}}{D(t)}
$$

With $\delta_{t}=\delta_{0} \beta^{t}$, the condition becomes: $1-\beta-p_{0} \delta_{0}+\delta_{0} \beta\left(p_{0}-p\right)>0$. Since $p_{0} \geq p$, a sufficient condition is $\delta_{0} \leq 1-\beta$, which asymptotically holds for large $T$ (Proposition 4).

Proposition 6. Under Axioms 1, 2, 3, and Assumption 2, preferences are sub-additive. 
Proof. The indifference conditions $(x, 0) \sim(y, t),(x, 0) \sim(z, s)$ and $(z, s) \sim\left(y^{\prime}, t\right)$ express as:

$$
\begin{aligned}
u(x) & =\left(1-p_{0} \delta_{0}-\ldots-p \delta_{s}-\ldots-p \delta_{t-1}\right) u(y) \\
u(x) & =\left(1-p_{0} \delta_{0}-\ldots-p \delta_{s-1}\right) u(z) \\
\left(1-p_{0} \delta_{0}-\ldots-p \delta_{s-1}\right) u(z) & =\left(1-p_{0} \delta_{0}-\ldots-q \delta_{s}-\ldots-p \delta_{t-1}\right) u\left(y^{\prime}\right)
\end{aligned}
$$

The equalities simplify to $\left(1-p_{0} \delta_{0}-\ldots-q \delta_{s}-\ldots-p \delta_{t-1}\right) u\left(y^{\prime}\right)=\left(1-p_{0} \delta_{0}-\ldots-p \delta_{s}-\right.$ $\left.\ldots-p \delta_{t-1}\right) u(y)$. Since $q \geq p, y^{\prime} \geq y$.

Proposition 7. Assume that $(i)$ intertemporal utility is time separable with discount factor $D(t)$, (ii) period utility has a power form: $u(x)=x^{\sigma}, \sigma>0$ and (iii) the consumer is impatient and not increasingly impatient. Let $y_{t}$ and $x_{t}$, be the maximal quantities the DM, from date 0 perspective, is willing to forego at date $t$ in exchange for one unit obtained respectively at date 0 or $t-1$. Then $y_{t}>\left(x_{t}\right)^{t}$.

Proof. Impatience implies $u\left(x_{t}\right)=D(t-1) / D(t)>1$, and $u\left(y_{t}\right)=D(0) / D(t)>1$ (with $u(1)=1)$. The ratio can broken down into a series of short-delay discount factors:

$$
\frac{D(0)}{D(t)}=\frac{D(0)}{D(1)} \frac{D(1)}{D(2)} \ldots \frac{D(t-1)}{D(t)}
$$

Let us note $x_{s}$ the maximal quantity the DM is willing to forego at date $s$ in exchange for one unit obtained at date $s-1, s=1, \ldots, t: u\left(x_{s}\right)=D(s-1) / D(s)$. Non-increasing impatience implies $u\left(x_{s}\right) \geq u\left(x_{t}\right) \forall s$. It follows that $u\left(y_{t}\right) \geq u\left(x_{t}\right)^{t}$ or $y_{t} \geq\left(x_{t}\right)^{t}$ if $u$ takes a power form. 


\section{Appendix B. The experiment}

\section{Experimental procedure}

I present the experimental procedure eliciting short-delay and long-delay preferences referred to in Subsection 6. A paper-and-pencil questionnaire was distributed at the beginning of the 2017-18 first semester to 32 students enrolled in an undergraduate introductory finance course in University of Orléans (France). In addition, the same questionnaire was given at the same period to 22 students enrolled in a graduate introductory insurance course in the same university. A total of 52 students filled the questionnaire. Two students did not wish to participate to the experiment. The questionnaire began with the following instructions (translated from French):

Before answering the questions,

- be aware that no "best answers" exist, only ones that best fit your preferences

- avoid being influenced by other students. Do not discuss your choices with them, and keep your answers confidential until the questionnaires are returned.

- make sure you understand all questions, take your time when answering.

The questionnaire contained two parts. The first part included six questions about short-delay trade-offs with varying front-end delays (from 0 to 5 weeks). The typical question, replicated six times with $n$ replaced by $0,1, \ldots, 5$, was the following:

Choose one of the two options:

receiving in $n$ weeks (during the break of the $n$-th session(s) of this course) a box containing 32 smarties.

receiving in $n$ weeks plus one hour and a half (at the end of the $n$-th session(s) of this course) a box containing 33 smarties. 
About half the questionnaires presented the questions with ascending $n$ (25 over 52), the others with descending $n$. The questionnaire was ended with the following information, which repeated what had been told to students before the distribution:

Draw procedure: once all questionnaires will be filled and returned, one of the six course sessions will be randomly selected by the throw of a six-sided die. If the die lands on 1, your choice for the current session will be implemented; if it lands on 2 , your choice of the session next week will be satisfied, etc. until the number 6 for your choice in 5 weeks.

After the return of all questionnaires, a voluntary student throws the die. The boxes of smarties were distributed to students at the moment of their choice the week selected by the die.

The second part of the questionnaire contained six questions about long-delay tradeoffs with varying delays (from 0 to 5 weeks). The typical question replicated six times, with $n$ replaced by $0,1, \ldots, 5$, was the following:

I am indifferent between receiving 32 smarties now or ... smarties in $n$ weeks plus one hour and a half, at the end of the $n$-th $\operatorname{session(s)}$ of this course.

Around half questionnaires presented the trade-offs with ascending $n$, the other half with descending $n$. Students were told that this set of questions were hypothetical and that the smarties that would make them indifferent would not be distributed.

\section{Results}

3 questionnaires out of 52 were discarded for incomplete or implausible answers (one student did not fill the second questionnaire, a second one wrote 0 and a third one 10000 for all questions in the second questionnaire). The fraction of subjects who preferred consuming at the earliest date was approximately the same whatever the ordering of the questions (Table 5).

42 subjects (86\%) did not change their choice with $n$, among whom 28 always chose the earliest option and 14 the latest one. Among the 7 subjects (14\%) who switched 
Table 5: Fraction of subjects preferring the early option in function of delay expressed in weeks $(N=49)$

\begin{tabular}{lcccccc}
\hline weeks & 0 & 1 & 2 & 3 & 4 & 5 \\
\hline ascending $n$ & 0.60 & 0.64 & 0.64 & 0.64 & 0.64 & 0.64 \\
descending $n$ & 0.71 & 0.67 & 0.67 & 0.67 & 0.67 & 0.67 \\
\hline total $n$ & 0.65 & 0.65 & 0.65 & 0.65 & 0.65 & 0.65 \\
\hline
\end{tabular}

at least once, 6 students switched only once and 1 subject switched twice. 3 students switched from an impatient to a patient choice and the other 3 from an impatient to a patient choice with $n$ increasing.

The average number of sweets $y_{n}$ which would make subjects indifferent between consuming a box of 32 smarties now and $y_{n}$ in $n$ weeks is approximately the same for the group who answered the questionnaire with ascending $n$ and the group with descending $n$ until $n=2$ (see Table 6 ). The quantities differ more significantly for $n>2$, with subjects being more impatient when $n$ is increasing. 42 subjects (86\%) reported non-decreasing quantities with $n$.

Table 6: Average number of chocolate sweets in $n$ weeks plus one hour and a half equivalent to 32 units consumed immediately $(N=49)$

\begin{tabular}{lcccccc}
\hline number of weeks & 0 & 1 & 2 & 3 & 4 & 5 \\
\hline ascending $n$ & 38 & 53 & 65 & 80 & 101 & 132 \\
descending $n$ & 40 & 51 & 64 & 74 & 85 & 97 \\
\hline total & 39 & 52 & 64 & 77 & 93 & 115 \\
\hline
\end{tabular}

Table 7 shows average $y_{n}$ for the subset of 42 subjects who reported a non-decreasing sequence (second row) and average $y_{n}$ for the 7 subjects who reported a sequence of $y_{n}$ with a decreasing part (third row). Most of them display stronger impatience for $n=0$ (between now and in one hour and a half), than for trade-offs with longer front-end delays. The quantities are approximately constant for $n>0$. 
Table 7: Average number of chocolate sweets in $n$ weeks plus one hour and a half equivalent to 32 units consumed immediately for subjects with non-decreasing sequences $(N=49)$

\begin{tabular}{lcccccc}
\hline number of weeks & 0 & 1 & 2 & 3 & 4 & 5 \\
\hline subjects with non-decreasing sequence & 40 & 55 & 69 & 84 & 103 & 129 \\
other subjects & 37 & 34 & 34 & 33 & 34 & 32 \\
\hline total & 39 & 52 & 64 & 77 & 93 & 115 \\
\hline
\end{tabular}

